\title{
Análisis interpretativo sobre la vacancia presidencial por incapacidad moral en el Perú
}

\author{
Interpretive analysis of the presidential vacancy due to moral \\ incapacity in Peru
}

\author{
Bardales-del-Aguila, Lionel [(D) 0000-0002-9| 10-4475]। \\ 'Universidad Nacional de San Martín, Tarapoto, Perú \\ Ibardales@unsm.edu.pe \\ Recibido: |4/| |/202|; \\ Aceptado: 15/12/2021; \\ Publicado: 20/01/2022
}

Resumen: El propósito del artículo fue analizar la figura de la vacancia presidencial por permanente incapacidad moral prescrita en el numeral 2 del art $113^{\circ}$ de la Constitución Política del Perú. El tipo de investigación fue cualitativa, de nivel descriptivo y diseño hermenéutico-interpretativo. Se aplicó las técnicas de interpretación jurídica y del derecho comparado. El estudio analiza la vacancia del Presidente de la República Martín Alberto Vizcarra Cornejo. Los resultados expresan que, no existen antecedentes en las constituciones de los países vecinos sobre esta figura, lo que sí presentan es "la incapacidad física y mental". En Estados Unidos, se aplica el "impeachment" o juicio político, es análogo a lo prescrito en los artículos $99^{\circ}$ y $100^{\circ}$ de Constitución Peruana sobre el "antejuicio" y "juicio político"; que, a diferencia de la vacancia por incapacidad moral, el proceso se inicia con una acusación por infracción constitucional, con contenido penal que determinan la destitución e inhabilitación del funcionario o la acusación ante la Corte Suprema. En conclusión, la categoría de la vacancia presidencial por permanente incapacidad moral, se superpone con el "antejuicio" y "juicio político" por carecer de contenido, son susceptibles de quedar bajo el criterio subjetivo y autoritario del congresista. Siendo necesaria la reforma de los artículos $113^{\circ}$, $99^{\circ}$ y $100^{\circ}$ de la Constitución Política a través de una Ley de Desarrollo, que aclare y precise el contenido de la vacancia presidencial por incapacidad moral y lo relacionado con el "antejuicio" y "juicio político".

Palabras clave: antejuicio político; incapacidad moral y física; incapacidad física y mental; juicio político

\begin{abstract}
The purpose of the article was to analyze the figure of the presidential vacancy due to permanent moral incapacity prescribed in paragraph 2 of article $113^{\circ}$ of the Political Constitution of Peru. The type of research was qualitative, descriptive level and hermeneutical-interpretive design. The techniques of legal interpretation and comparative law were applied. The study analyzes the vacancy of the President of the Republic Martín Alberto Vizcarra Cornejo. The results express that, there is no precedent in the constitutions of neighboring countries on this figure, what they do present is "physical and mental disability". In the United States, the "impeachment" or political trial is applied, it is analogous to what is prescribed in articles $99^{\circ}$ and $100^{\circ}$ of the Peruvian Constitution on the "preliminary trial" and "political trial"; that, unlike the vacancy due to moral incapacity, the process begins with an accusation for constitutional infraction, with criminal content that determines the dismissal and disqualification of the official or the accusation before the Supreme Court. In conclusion, the category of the presidential vacancy due to permanent moral incapacity, overlaps with the "preliminary judgment" and "political judgment" due to lack of content, they are likely to remain under the subjective and authoritarian criteria of the congressman. Being necessary the reform of articles $113^{\circ}, 99^{\circ}$ and $100^{\circ}$ of the Political Constitution through a Development Law, which clarifies and specifies the content of the presidential vacancy due to moral incapacity and what is related to the "preliminary judgment" and "impeachment".
\end{abstract}

Keywords: political prejudice; moral and physical incapacity; physical and mental disability; impeachment

Cómo citar / Citation: Bardales-del-Aguila, L. (2022). Análisis interpretativo sobre la vacancia presidencial por incapacidad moral en el Perú. Revista Científica Ratio lure, 2(I), e276. https://doi.org//0.5 I252/rcri.v2il.276 


\section{Introducción}

La crisis política en Perú se ha convertido en una constante y forma parte del historial de vida republicana. Al realizar un breve recorrido histórico de esta situación; juristas y constitucionalistas, como García, Landa, Galindo, Praeli y otros, consideran que ello tiene que ver que ver con la aplicación de modelos políticos que por lo general han oscilado entre un régimen presidencialista fuerte, un régimen presidencial moderado, en permanente conflicto con el modelo parlamentario; por lo que consideran que en Perú prima un modelo híbrido denominado Presidencialismo parlamentario.

Landa Arroyo, citado por Melgar Bendezú (2019); menciona que la vida política constitucional en Perú ha dependido de los hechos políticos y militares, y que los operadores políticos no han sabido ponerse de acuerdo y lograr consensos para un pacto social y el logro de un estado de derecho duradero.

En 1912 García Calderón, explicaba como causa de ello a que en el Perú no contaba con una clase política con la suficiente formación ni con el hábito de la libertad, dando lugar a la concentración de poder, la carencia de control, "la evolución política peruana se expresara en dos formas: exceso de gobierno o de anarquía” (Melgar Bendezú, 2019).

Flores Galindo, citado por Melgar Bendezú (2019), hace referencia a la inestabilidad política del país; y que ella tuviera como causa "al vacío dejado por la aristocracia colonial, brecha que dejó el control de los aparatos estatales en el ejército".

En este contexto, el "constitucionalismo peruano"; adoptó las teorías y modelos políticos desarrollados por los maestros del contractualismo como Montesquieu, Rousseau, Locke y otros que postulan la teoría de la separación de poderes y el control político como recurso del sistema democrático para evitar el abuso de poder y la instauración de la tiranía.

El principio de la separación de poderes se recoge en la Declaración del Buen Pueblo de Virginia y en las Constituciones de Maryland y North Carolina; pero sobre todo inspiraba las Constituciones de Pensilvania y Vermount. Las dos instituciones más importantes de la Constitución de Pensilvania, el Consejo y la Asamblea legislativa, eran elegidos por el pueblo y la pertenencia a ambas era incompatible. En 1776 la doctrina de la separación de poderes era el único principio coherente de gobierno constitucional sobre el que establecer una Constitución que rechazase la monarquía y la aristocracia (Domingo García, I991).

Luego de instaurada la República, el debate se trasladó a determinar la forma de gobierno, en los modelos vigentes estaban presentes el presidencialismo y el parlamentarismo. Según García (I98I) citado en (Domingo García, 199I) "Al igual que el resto de la América Latina, el Perú siguió el modelo presidencial creado por los Estados Unidos". El presidencialismo consiste en entregar el centro de decisiones al jefe del Estado, quien, al mismo tiempo, es jefe de Gobierno, dentro de un esquema en el cual hay un sistema rígido de separación de poderes (no hay ministros que refrenden actos del presidente ni tampoco controles políticos del Parlamento sobre el Ejecutivo). El Ejecutivo no debe su elección al Congreso, sino al pueblo.

Por otro lado, el parlamentarismo, que tiene su origen en Europa bajo este modelo, es el Congreso o Legislativo quien tiene el control del poder estatal, el Jefe de Estado es designado por el Legislativo, existe un poder dual, jefe de Estado y jefe de Gobierno por otro, existe el 
control político; en caso de conflicto entre ambos poderes, puede optarse por la disolución del Congreso, convocando de inmediato a elecciones generales (Domingo García, 1991).

De igual forma García (1981) citado en (Domingo García, 1991) menciona que, a raíz de la constitución francesa de 1958 , se instituye una nueva forma de gobierno llamado "semipresencial", término usado por Duverger. El cual tendría las siguientes características: a) elección del presidente por sufragio universal; b) atribuciones propias y significativas del presidente de la República, y c) existencia paralela de un Gobierno (Gabinete y primer ministro), que tiene actividades y poderes propios e independientes del presidente y que además responde ante el Parlamento. Señala Duverger que estos elementos deben ir acompañados unos de otros para que la categoría por él creada pueda ser empleada con propiedad.

Como se puede observar el actual sistema político peruano normado en la Constitución Política de 1993, ha establecido un sistema "híbrido" o "mixto" o "semipresidencial". En efecto, si bien el Perú aceptó desde un principio el modelo presidencial de Gobierno, fue introduciendo diversos elementos de control al presidente, que venían de la tradición parlamentaria, todo lo cual empezó a mediados del siglo xix y culminó, como ya se indicó, con la Carta de 1933 (Domingo García, 1991).

García concluye indicando que es complicado afirmar que la forma de gobierno del Perú sea mixta, porque, sería una nueva creación y ello no sucede así, indicando que se trataría de un "presidencialismo disminuido, atenuado o frenado, toda vez que las grandes decisiones las tiene en última instancia, el presidente de la República, atemperado por controles y, en cierto sentido, por la opinión pública y los partidos políticos” (Domingo García, 1991).

Atendiendo a García, se podría inferir que, en el Perú, la disputa estaría viva, entre el Presidencialismo y el Parlamentarismo, por lo que muchas veces es recurrente escuchar en que "El parlamento es el primer poder del estado". Quizá esta dualidad ha llevado al constituyente a establecer instituciones como el de "la cuestión de confianza", "el cierre del Congreso", "la vacancia presidencial”, "la censura”, "la acusación constitucional”, "el antejuicio político" y el "juicio político". Como recursos de freno y contrapeso a la acción por parte de ambos poderes del Estado.

Es a partir del 2000, en que el país ingresa a una relativa estabilidad política, que fuera interrumpida, por la instauración de un nuevo tipo de golpe de Estado, ya no ejecutado por las fuerzas armadas, sino desde las entrañas mismas de los órganos constitucionales, sea del poder ejecutivo o el legislativo. Ello a raíz de las graves denuncias de corrupción por los casos "LavajatoOdebrecht" y "Cuellos Blancos" que involucran a ex Presidentes de Perú, funcionarios del estado y magistrados de la Corte Suprema, del Ministerio Público y de otros organismos constitucionales autónomos, en aplicación de la norma constitucional.

En este artículo analizamos una de las figuras del control político establecidos en el inciso 2, artículo II 3 de la Constitución Política que faculta al Legislativo a vacar al Presidente por la "permanente incapacidad moral”. Que como es conocido tuvo como epílogo la vacancia del Presidente Martín Alberto Vizcarra Cornejo.

Esta vacancia fue el detonante de una serie de acontecimientos causados por la pugna y la permanente disputa entre el Legislativo y el Ejecutivo, dando lugar a la protesta social y movilización de amplios sectores de la sociedad cuyo desenlace fue muerte de dos manifestantes, obligando a la renuncia de los nuevos ministros y del Presidente designado por el Congreso. El 
Congreso de la República eligió como nuevo Presidente al congresista Francisco R. Sagasti Hoccháusler. De esta manera Perú, en un fenómeno sin precedentes; tuvo tres presidentes en una semana, evidenciando una agitada y complicada situación política (Sierra Casanova, 202I).

A consecuencia de la elección del nuevo Presidente de la República, Pedro Castillo Terrones, los partidos políticos de oposición, con mayoría congresal; se resisten a reconocer el triunfo del nuevo gobernante e insistentemente vienen anunciando la aplicación de la vacancia presidencial por "incapacidad moral". Ante lo cual Legislativo y Ejecutivo se centraban en una pugna por el "control político". Llevando a proponer modificaciones a la Constitución Política en torno a las figuras de la "cuestión de confianza", "cierre del congreso" y "la vacancia por incapacidad moral".

Ante esta situación, es pertinente analizar la figura de la "permanente incapacidad moral declarada por el congreso”, planteándonos las siguientes interrogantes: ¿Cuáles son los criterios de contenido para la determinación de la incapacidad moral del Presidente?, ¿Las decisiones del Legislativo para la determinación de la vacancia presidencial por incapacidad moral se encuentran debidamente motivados?, ¿Existe claridad conceptual sobre la figura de la incapacidad moral establecidos en la constitución Política?, ¿Cuál fue el motivo o naturaleza de esta figura por la que el legislador optó por esta norma?, ¿Constituye la vacancia por incapacidad moral la figura más adecuada para resolver este tipo de conflictos entre el Ejecutivo y el Legislativo?.

El artículo busca describir el proceso de vacancia por incapacidad moral en el Perú, interpretar la figura de la vacancia por incapacidad moral aplicando las técnicas de la interpretación jurídica: literal, histórica, sistemática, filosófica y del derecho comparado y proponer las medidas correctivas necesarias para resolver la vaguedad e indeterminación de la "vacancia por incapacidad moral".

\section{Materiales y métodos}

Se empleó una investigación cualitativa, diseño hermenéutico interpretativo, los métodos de investigación aplicados fueron: El estudio de caso, para lo cual se analizó la vacancia por incapacidad moral del ex Presidente de la República Martín Alberto Vizcarra Cornejo, las técnicas interpretativas judiciales y constitucionales como: análisis literal, histórico, sistemático, filosófico y del derecho comparado. Para lo cual se recurrió a la revisión de diferentes fuentes bibliográficas.

Como es conocido, la investigación cualitativa no pretende probar hipótesis, así el presente artículo se limita a interpretar desde las perspectivas mencionadas la figura de la vacancia presidencial por incapacidad moral prescrita en el inciso 2 del artículo $113^{\circ}$ de la Constitución Política en el contexto del sistema político peruano. 


\section{Resultados y discusión}

\section{I. La incapacidad moral en las constituciones de Estados Unidos y América Latina}

García Chavarri (2013) desarrolló un estudio histórico, jurídico y político sobre esta figura constitucional, fijando sus antecedentes en el juicio político o "Impeachment" inglés y norteamericano, en los siguientes panoramas:

\section{Estados Unidos}

Según García, la Constitución Federal de los Estados Unidos de Norteamérica de 1,787 establece en su artículo $2^{\circ}$, primera sección, cláusula $6^{\circ}$ :

En caso de que el Presidente sea separado de su puesto, de que muera, renuncie o se incapacite para dar cumplimiento a los poderes y deberes del referido cargo, este pasará al Vicepresidente y el Congreso podrá prever por medio de una ley el caso de separación, muerte, renuncia o incapacidad, tanto del Presidente como del Vicepresidente, y declarar qué funcionario fungirá como Presidente hasta que desaparezca la causa de incapacidad o se elija un Presidente.

De lo anterior se colige que, las causales de vacancia están delimitadas, por las cuales el Congreso norteamericano las asume como tales: sea muerte, renuncia, incapacidad. En caso de la separación por juicio político denominado impeachment; obedece a un proceso con las debidas garantías en el que el Presidente es acusado por el tribunal de Justicia a través del Senado; en la mayoría de juicios políticos han concluido dando la razón y absolviendo de las acusaciones a los Presidentes y otras figuras del Poder político o judicial.

\section{Argentina}

El artículo $88^{\circ}$ de la Constitución Nacional de la República Argentina de 1994 señala que:

En caso de enfermedad, ausencia de la Capital, muerte, renuncia o destitución del presidente, el Poder Ejecutivo será ejercido por el vicepresidente de la Nación. En caso de destitución, muerte, dimisión o inhabilidad del presidente y vicepresidente de la Nación, el Congreso determinará qué funcionario público ha de desempeñar la Presidencia, hasta que haya cesado la causa de la inhabilidad o un nuevo presidente sea electo.

Como se puede observar la Constitución Argentina, no prevé causales de vacancia para el cargo de Presidente, solo se refiere a casos de destitución, muerte, dimisión o inhabilidad, otorga la facultad al congreso determinar al reemplazante en forma temporal.

\section{Bolivia}

La figura de la vacancia constitucional en Bolivia se encuentra normada en la Constitución Política de 2009, la cual contempla la figura de la vacancia presidencial bajo los términos de cesación del mandato, prescrito en los artículos $170^{\circ}$ y $171^{\circ}$; en el que se observa que las causales de la cesación del mandato son objetivas: muerte, renuncia a ser aceptada, ausencia o impedimento definitivos, sentencia condenatoria ejecutoriada y revocatoria popularmente acordada. Las causales se encuentran fijadas en forma clara y precisa. 


\section{Brasil}

El régimen presidencialista de la República Federativa de Brasil, no precisa de manera concreta la vacancia presidencial; el artículo 83 de la Constitución establece que "O Presidente e o VicePresidente da República não poderão, sem licença do Congresso Nacional, ausentarse do País por período superior a quinze dias, sob pena de perda do cargo".

Como se observa las causales de vacancia están precisadas como los dispuesto sobre los plazos para la toma de posesión de mando o el no regreso al país en el plazo indicado por el Congreso. Los artículos $83^{\circ}$ y $85^{\circ}$ de la Constitución brasilera, establece las causales de vacancia por incumplimiento de funciones, que en caso de delitos comunes sentenciado por el Tribunal Federal Superior. En este caso tiene parecido con el juicio político -impeachment- cuya acusación es aprobada por la Cámara de Diputados y resuelta por el Senado.

\section{Chile}

La Constitución Política de la República de Chile de 1980, en el artículo 29|: en forma extensa se refiere a las causales de sucesión "por impedimento temporal, sea enfermedad, ausencia del territorio u otro grave motivo", estableciendo un orden de precedencia sucesoria de presentarse la ausencia del Presidente de la República en los términos siguientes:

El Presidente de la República no pudiere ejercer su cargo, le subrogará, con el título de Vicepresidente de la República, el Ministro titular a quien corresponda de acuerdo con el orden de precedencia legal. A falta de éste, la subrogación corresponderá al Ministro titular que siga en ese orden de precedencia $y$, a falta de todos ellos, le subrogará sucesivamente el Presidente del Senado, el Presidente de la Cámara de Diputados y el Presidente de la Corte Suprema.

En el segundo párrafo, se refiere a la "vacancia del cargo de Presidente de la República, se producirá la subrogación como en las situaciones del inciso anterior"; estableciendo los procedimientos para elegir al sucesor, que en caso de producirse faltando menos de dos años para la próxima elección, el Presidente es elegido por el congreso, si la vacancia se produjere faltando dos años o más para la próxima elección, el Vicepresidente está facultado a convocar a elecciones presidenciales. El mandato del Presidente elegido es para completar el periodo interrumpido.

\section{Colombia}

La vacancia presidencial se encuentra regulada en el artículo $194^{\circ}$ de La Constitución de Colombia de 1991, bajo los términos de "falta absoluta". Así, se lee lo siguiente:

Artículo 194. Son faltas absolutas del Presidente de la República su muerte, su renuncia aceptada, la destitución decretada por sentencia, la incapacidad física permanente y el abandono del cargo, declarados éstos dos últimos por el Senado. Son faltas temporales la licencia y la enfermedad, de conformidad con el artículo precedente y la suspensión en el ejercicio del cargo decretada por el Senado, previa admisión pública de la acusación en el caso previsto en el numeral primero del artículo 175.

Como puede leerse, la vacancia presidencial colombiana responde a causales objetivas: "muerte, renuncia aceptada, destitución por sentencia condenatoria, incapacidad física 
permanente y abandono del cargo". Todos estos supuestos son comprobables en la que su comprobación es verificable (muerte, destitución por sentencia, incapacidad física permanente) sin que ello signifique una evaluación del desempeño presidencial, el cual, para ser compatible con el modelo de sistema de gobierno, debe extenderse por todo el periodo fijado constitucionalmente.

\section{Ecuador}

La Constitución de la República de Ecuador de 2008 regula la figura de la vacancia presidencial en los siguientes términos: Art. 145.- La Presidenta o Presidente de la República cesará en sus funciones y dejará vacante el cargo en los casos siguientes: I. Por la terminación del período presidencial, 2. Por renuncia voluntaria aceptada por la Asamblea Nacional, 3. Por destitución, de acuerdo a lo dispuesto en la Constitución, 4. Por incapacidad física o mental permanente que le impida ejercer el cargo, certificada de acuerdo con la ley por un comité de médicos especializados, y declarada por la Asamblea Nacional con los votos de las dos terceras partes de sus integrantes, 5. Por abandono del cargo, comprobado por la Corte Constitucional y declarado por la Asamblea Nacional con los votos de las dos terceras partes de sus integrantes, 6. Por revocatoria del mandato, de acuerdo con el procedimiento establecido en la Constitución".

Se observa que el constituyente ecuatoriano, ha tenido mucho cuidado en fijar las causales de la cesación del Presidente de la República, la cual pasa por ser comprobada por otra instancia, reduciendo la posibilidad de que el congreso sea la instancia única para esta decisión. Así, por ejemplo, "la causal de incapacidad mental permanente -utilizada para el caso de Abdalá Bucaram en 1997- se encuentra meticulosamente detallada al exigirse que ella se encuentre certificada de acuerdo con la ley por un comité de médicos especializados".

Quintero Jaramillo \& López Viteri (2018), elaboró un cuadro comparativo donde analiza los artículos de las constituciones políticas de los diferentes países latinoamericanos. En el caso de las constituciones políticas de los países de América Central, Costa Rica, El Salvador, Guatemala, México, Panamá y República Dominicana, no contemplan la figura de la cesación por incapacidad física o mental, menos aún mencionan la "incapacidad moral" como causas de incapacidad y cesación.

Tabla I. Análisis comparativo de las Constituciones políticas de los países de América del sur sobre vacancia presidencial

\begin{tabular}{|c|c|c|c|c|c|}
\hline Argentina & Chile & Paraguay & Perú & Uruguay & Venezuela \\
\hline $\begin{array}{c}\text { Art. } 88 \\
\text { Contempla } \\
\text { la cesación } \\
\text { por } \\
\text { Enfermedad } \\
\text { y la decisión } \\
\text { última la } \\
\text { tomará el } \\
\text { Congreso. }\end{array}$ & $\begin{array}{c}\text { Art. } 29 \\
\text { Contempla la } \\
\text { cesación por } \\
\text { Enfermedad y } \\
\text { la decisión } \\
\text { última de la } \\
\text { Cámara de } \\
\text { Diputados }\end{array}$ & $\begin{array}{c}\text { Art. } 225 \\
\text { No existe } \\
\text { la figura de } \\
\text { cesación } \\
\text { por } \\
\text { enfermedad } \\
\text { o incapacidad } \\
\text { física o mental }\end{array}$ & $\begin{array}{c}\text { Art.II3 } \\
\text { Estipula } \\
\text { permanente } \\
\text { incapacidad } \\
\text { moral o física, } \\
\text { declarada por } \\
\text { el Congreso }\end{array}$ & $\begin{array}{c}\text { Art. I55 } \\
\text { En caso de } \\
\text { renuncia, } \\
\text { incapacidad } \\
\text { permanente } \\
\text { Declarada por } \\
\text { la Cámara de } \\
\text { Senadores }\end{array}$ & $\begin{array}{c}\text { Art. } 233 \\
\text { Incapacidad } \\
\text { física o mental } \\
\text { permanente } \\
\text { certificada por } \\
\text { una junta } \\
\text { médica } \\
\text { Aprobación de } \\
\text { la Asamblea } \\
\text { Nacional. }\end{array}$ \\
\hline
\end{tabular}

Fuente: Reproducido de Jaramillo \& López Viteri (2018). 
Según la Tabla I, tres Constituciones no poseen cesación por incapacidad física y/o mental. A diferencia de las Repúblicas de Perú, Uruguay y Venezuela que abordan el término incapacidad de manera similar. Es necesario destacar que la Constitución del Perú es la única que alude al término de "permanente incapacidad moral y física". Mientras que Uruguay solamente expresa la incapacidad permanente. Por último, Venezuela al igual que Ecuador, determina la cesación por incapacidad fisica o mental, que en el caso de estos dos países mencionan que debe ser certificada por una junta médica y la decisión pasa por la aprobación del Congreso y/o la Asamblea Nacional.

\subsection{La vacancia por incapacidad moral desde las Constituciones en el Perú}

Bregaglio et al. (202l) mencionan que el primer antecedente de la vacancia presidencial por incapacidad moral lo encontramos en las constituciones de 1828 y 1834 , si bien es cierto no se refieren al término "vacancia" sino con los términos de "reemplazo" del Presidente "en casos de imposibilidad física o moral". La vacancia como tal, fue incluida por la Constitución de I834; aunque solo se consideró la "incapacidad física y mental", estando exenta el término "incapacidad moral".

Por su parte, García Chavarri (2013) menciona que fue la Constitución Política de 1839 "la primera en contemplar la figura de la incapacidad moral como causal de vacancia en el ejercicio del cargo presidencial" bajo los términos de "perpetua imposibilidad moral" (artículo $\left.81^{\circ}\right)$. En la Constitución de 1856 en su artículo $83^{\circ}$ aparece normada bajo el término de “incapacidad moral"; igualmente en la Carta de 1860 (artículo $88^{\circ}$ ), se menciona con los términos de "perpetua incapacidad moral del Presidente".

Posteriormente las Constituciones de 1867, 1920, 1979 y 1993 contemplan la causal de incapacidad moral, la Carta de 1920 en su artículo $115^{\circ}$, inciso I, hace el agregado de “permanente incapacidad moral del Presidente declarada por el congreso". Este último párrafo aparece en el texto constitucional de 1933 (artículo 144 , inciso I). La Constitución de 1979 lo establece en el artículo $206^{\circ}$, inciso I. Finalmente, la Carta actual de 1993 contempla la causal bajo la frase de "permanente incapacidad moral" (artículo II $3^{\circ}$, inciso 3).

El primer Presidente del Perú en ser vacado bajo el recurso de la causal de incapacidad moral fue José Mariano de la Riva Agüero y Sánchez Boquete en 1823, dicha vacancia se debió a las pugnas políticas entre Riva Agüero y el Congreso.

Según el Tribunal Constitucional (2020), Sentencia recaída en el Expediente $\mathrm{N}^{\circ} 0002-$ 2020-CC/TC, voto singular del magistrado Espinoza Saldaña, párr. 49. Aclara: El retiro de José Mariano de la Riva Agüero y Sánchez Boquete de la Presidencia de la República por parte del Congreso en 1823 es referido como el primer antecedente histórico de la aplicación de la vacancia presidencial por incapacidad moral. Sin embargo, cabe resaltar que en dicha época esta figura aún no formaba parte del ordenamiento jurídico peruano.

En 1914, Guillermo E. Billinghurst Angulo también fue vacado en aplicación de la causal de incapacidad moral. Como en el caso anterior, y tras un intento de disolver el Congreso y convocar a consulta popular, determinaron su destitución, causada por su mala relación entre el ejecutivo y el Legislativo.

El año 2000 registra la vacancia presidencial por incapacidad moral del entonces Presidente Alberto Fujimori Fujimori. Como es sabido, Alberto Fujimori, fuga del país, y desde 
Japón vía fax comunica al Congreso de la República su renuncia al cargo. Este, no acepta la renuncia y declara la vacancia de su mandato por incapacidad moral, la que fue acordada por el voto aprobatorio de la mayoría simple de los congresistas presentes en el hemiciclo (García Chavarri, 2013).

El proceso de vacancia presidencial por "permanente incapacidad moral" de Pedro Pablo Kuczynski, se desarrolla en dos etapas: La primera, fue rechazada logrando 79 votos a favor, 19 en contra y $2 \mathrm{I}$ abstenciones. Para declararse la vacancia se necesitaba de una mayoría de dos tercios del total de 130 congresistas ( 87 votos a favor).

La "crisis presidencial" recrudeció luego de que se dieran a conocer documentos remitidos por la empresa Odebrecht a una comisión investigadora del Congreso, según los cuales dicha compañía había realizado años atrás pagos por servicios recibidos de las empresas First Capital y Westfield Capital, propiedad de Kuczynski. Dadas las sospechas de actos de corrupción, la oposición en el Congreso solicitó al presidente su renuncia o de lo contrario iniciarían para declarar la vacancia. El I 4 de diciembre, el presidente anunció que no renunciaría.

Esto aceleró el segundo pedido de vacancia agravado por los hechos y acontecimientos políticos sobre negociaciones indebidas entre PPK y un sector de la bancada fujimorista, referidos a la compra de votos de respaldo a cambio de la medida de prisión de Fujimori. El I5 de marzo del 2018, el Congreso volvió a aprobar la moción de vacancia al presidente. Esta vez fue por "incapacidad moral". La moción tenía el respaldo mayoritario del Congreso; obligando a Kuczynski a renunciar un día antes. La vacancia estaba cantada porque si no renunciaba, hubiese terminado vacado en aplicación del numeral $2^{\circ}$ del artículo $113^{\circ}$ de la Constitución Política del Perú. Asumiendo el mandato presidencial el Vicepresidente de la República.

En el 2020, en pleno estado de emergencia nacional por la pandemia del COVID-19; se produce la vacancia presidencial de Martín Vizcarra, en un hecho sin precedentes el Congreso de la República, en aplicación del artículo $113^{\circ}$, numeral 2 de la Constitución Política acuerda la vacancia presidencial en aplicación de la "permanente incapacidad moral". Esto como resultado de unas persistentes controversias entre el Ejecutivo y Legislativo, ocasionados anteriormente por el "cierre del congreso" y por la debilidad del Ejecutivo al no contar con representantes en el Parlamento.

En los cuatro ejemplos mencionados anteriormente, se observaron las dificultades de la incapacidad moral como causal de vacancia del Presidente de la República. En los casos de José Mariano de la Riva Agüero y Sánchez Boquete, Guillermo E. Billinghurst Angulo y Vizcarra; las causas se deben a las tensiones entre el Poder Ejecutivo y el Legislativo y al pésimo manejo de las relaciones entre los poderes del Estado.

En ese contexto podemos colegir que la justificación que se dio a la resolución de la pugna por el poder político entre ambos poderes del Estado fue establecer la incapacidad moral, cuando a todas luces se evidencia que son las motivaciones políticas y la incapacidad de establecer soluciones consensuadas a los problemas del país las que determinaron la terminación del ejercicio del cargo presidencial. Es decir, finalmente la cuestión moral, "se escondió más bien una valoración propia de un juicio político".

En la Tabla 2, elaborada por Bregaglio et al. (202I), se presenta la cronología de constituciones del Perú y la regulación sobre la incapacidad moral como causal de vacancia presidencial. 
Tabla 2. Regulación de vacancia por incapacidad moral en las constituciones peruanas

\begin{tabular}{|c|c|}
\hline Constitución & Regulación de la vacancia por incapacidad moral \\
\hline 1839 & $\begin{array}{c}\text { Art. } 81 \text {.- La presidencia de la República vaca de }(. . .) \text { derecho, por } \\
\text { admisión de su renuncia, perpetua imposibilidad física o moral, y } \\
\text { término de su período constitucional. }\end{array}$ \\
\hline 1856 & $\begin{array}{l}\text { Art. 83.- La Presidencia de la República vaca de derecho: (...) Por } \\
\text { incapacidad moral o física. }\end{array}$ \\
\hline 1860 & $\begin{array}{l}\text { Art. 88.- La Presidencia de la República vaca además del caso de } \\
\text { muerte: I. Por perpetua incapacidad física o moral del Presidente. }\end{array}$ \\
\hline 1867 & Art. 80.- Vaca de derecho: (...) 2. Por incapacidad moral o física. \\
\hline 1920 & $\begin{array}{c}\text { Art. I I5.- La presidencia de la República vaca, además del caso de } \\
\text { muerte: I. Por permanente incapacidad física o moral del } \\
\text { Presidente declarado por el Congreso }\end{array}$ \\
\hline 1933 & Art. I44.- La Presidencia de la República vaca, además del caso de \\
\hline 1979 & $\begin{array}{l}\text { Art. 206.- La Presidencia de la República vaca, además del caso de } \\
\text { muerte por: I. Incapacidad moral o permanente incapacidad física } \\
\text { declarada por el Congreso. }\end{array}$ \\
\hline 1933 & $\begin{array}{l}\text { Art. II 3.- (...) La Presidencia de la República vaca por: (...) 2. Su } \\
\text { permanente incapacidad moral o física, declarada por el Congreso. }\end{array}$ \\
\hline
\end{tabular}

Fuente: Reproducido de Bregaglio et al. (202I).

\subsection{Sobre el concepto de incapacidad moral como causal de vacancia presidencial}

León Hilario (2017) considera que el término "incapacidad moral", proviene del derecho canónico y del derecho privado francés, en el que se denomina "incapacité morale" como sinónimo de "incapacidad intelectual", ajeno pues a toda referencia a las reglas morales y éticas. Clásicamente el término fue empleado en el derecho de familia, esta figura se encuentra registrada en el derecho francés del siglo XIX, en el que era corriente el uso de los términos de "incapacidad moral y física". "Los dos adjetivos vienen a conformar. Así, una unidad sintagmática, donde lo "físico" se refiere a discapacidad "motriz", y lo "moral" a la discapacidad intelectiva, espiritual y psíquica". Igualmente, los italianos, utilizan la expresión "incapacità morale", cuando se pone en duda la capacidad intelectual de las personas; por ende, no hace alusión al accionar inmoral y antiético de la persona.

En el caso del artículo $113^{\circ}$ de la Carta Política, se habla de "incapacidad moral" no se refiere a la discapacidad producida por enfermedades mentales. Por otro lado, la discapacidad "mental" se diferencia de la discapacidad física; ya que la primera desde el campo de la psicología y la psiquiatría abarcan enfermedades o desórdenes mentales como: La esquizofrenia, las manías, la depresión, el Alzheimer y otros; mientras, que por discapacidad física sería el estado comatoso o vegetativo, la esclerosis múltiple u otros que minen la capacidad para tomar decisiones, entender y querer.

Si a ello le agregamos el término de "incapacidad moral permanente", surge la imprecisión al calificar una conducta o práctica inadecuada (moral) como permanente e irreversible, como si se tratara de una discapacidad física. 


\subsection{El concepto jurídico de capacidad e incapacidad desde el Código Civil}

Los conceptos jurídicos de capacidad e incapacidad se encuentran normados en el Código Civil, el artículo $42^{\circ}$ del Código Civil señala que "tienen plena capacidad de ejercicio de sus derechos civiles las personas que hayan cumplido dieciocho años de edad salvo lo dispuesto en los artículos $43^{\circ}$ y $44^{\circ}$ ", que se refieren a la incapacidad.

El Código Civil, distingue la incapacidad absoluta de la incapacidad restringida en los artículos 43 y 44; el numeral 2 del artículo 43 del Código Civil sobre la incapacidad absoluta, señala: Que son absolutamente incapaces: "Los menores de dieciséis años, salvo para aquellos actos determinados por la ley".

La Casación $\mathrm{N}^{\circ}$ 683-2016-Callao; define al incapaz absoluto quien se encuentra privado por cualquier causa de discernimiento, y precisa que: "discernir jurídicamente es diferenciar entre hacer o no hacer algo y conocer si ese "algo" es bueno o malo, o distinguir entre el bien y el mal, lo lícito o lo ilícito, lo que está o no permitido, lo que beneficia o es perjudicial” (GuerraCerrón, 2018).

De la definición anterior colegimos que los magistrados de la Sala Civil Suprema, amplía el concepto de privación del discernimiento, no sólo los procesos mentales intelectuales, sino también a los del razonamiento moral y ético; entonces si sería posible incluir dentro de la incapacidad absoluta, dichos criterios, que llevarían a una persona a no reconocer que actos son buenos o malos y con ellos a carecer de la censura voluntaria y autónoma propios del razonamiento moral, llevando a esta al plano de la "psicopatía".

El código civil también define la capacidad de ejercicio restringida, tal es así que el artículo 44 señala: Tienen capacidad de ejercicio restringida: I) Los mayores de dieciséis y menores de dieciocho años de edad. 2) Los pródigos. 3) Los que incurren en mala gestión. 4) los ebrios habituales, 5) Los toxicómanos, \&) Los que llevan pena que lleva anexa la interdicción civil. 7) Las personas que se encuentren en estado de coma, siempre que no haya designado un apoyo con anterioridad.

En este contexto observamos que el Código civil, también incorpora como capacidad del ejercicio restringida: "los que incurren en mala gestión". Aquí resulta claro, que El Presidente de la República como máxima autoridad del Ejecutivo que personifica la nación es el llamado a mostrar una gestión óptima cuyos resultados van al logro del bienestar general de la población y si en el ejercicio de sus funciones el Presidente de la República, incurre en mala gestión, es pasible de ser calificado como restringido en sus capacidades.

Teniendo en cuenta los normado desde el Código Civil y el Procesal Civil, es factible establecer las precisiones legales de "la incapacidad moral permanente"; de tal manera, los artículos 43.2, 44.2 y 44.3 lo expresan como personas "privadas de discernimiento", "retardados mentales" y "aquellos que adolecen de deterioro mental que les impide expresar su libre voluntad"; en ambas situaciones "se persigue por negarles estado de lucidez conforme a una declaración de incapacidad” (Mezarino, s. f.). 


\subsection{La vacancia por incapacidad moral y su relación con el impeachment, juicio político y el antejuicio}

Gallo, citado por García Chavarri (20I3), indica que la finalidad del impeachment es la protección del Estado. Su propósito no es otro que la severa moralización administrativa y tiene que ver con la verificación de la ausencia de una conducta calificable como "virtuosa". Busca separar del cargo a quien es indigno de él, inclusive previendo que dicho funcionario no vuelva a ocupar otro cargo público en el futuro.

García Chavarri (2013) citando a (Salgado 2003: 172) afirma: El impeachment sanciona la falta política, las conductas perjudiciales al Estado, las acciones contrarias a la dignidad del cargo que un alto funcionario ostenta. En el impeachment, pues, se "juzga" con inequívoco carácter político el "desempeño de las funciones, en cuyo ejercicio puede atentarse al interés público o se puede incurrir en violaciones normativas -sea a la Constitución o a las leyes- o cometer delitos políticos o incluso comunes.

\subsection{El juicio político o impeachment en Inglaterra}

El juicio político en el sistema político inglés conocido como impeachment "es una institución de naturaleza política propiamente, que se lleva a cabo a través del Parlamento o el Congreso. Sus fines, objetivos y actos materia de su procedimiento son de absoluta índole política". En Inglaterra el impeachment, "era entendido como la acusación llevada por los comunes a la Cámara Alta o de los Lores".

Esta institución nació en Inglaterra en el siglo XIV, el primer caso ocurrió en I376, durante el reinado de Eduardo III. El Parlamento, encargó a Sir Peter de la Mare que formule ante el Consejo, presidido por el duque de Gaunt, el requerimiento de examinar las cuentas de la administración. Como resultado de la investigación, acusaron ante la Cámara de los Lores a Lord Latimer (consejero privado y Chamberlain del Rey) y a Richard Lyons (comerciante) por un conjunto de graves malversaciones $y$ fraudes financieros.

Según García Chavarri (2013), el impeachment más importante de la política inglesa fue el seguido a Warren Hastings, ex virrey de las Indias. Comenzó en 1786 y concluyó en 1795 con la absolución de los cargos.

El último caso de impeachment británico data de 1805. Henry Dundas, Lord Melville, primer Lord Tesorero del Almirantazgo, fue acusado de prevaricación e irregularidades en el ejercicio de su cargo. Frente a ello, Lord Melville prefirió renunciar a su puesto; y no obstante ser posteriormente eximido, se consideró necesario eliminar su nombre de la lista de miembros del consejo privado.

A partir de 1688 , al fin al reinado de Jacobo II, el impeachment o "juicio político" comenzó a perder utilidad en Inglaterra a favor de la institución de la responsabilidad política, en virtud de la cual un ministro (o todo el gabinete, según el caso) era removido mediante el simple ejercicio del voto de censura o la denegatoria del voto de confianza, que lo obligaban a dimitir.

De este modo, el sistema inglés de responsabilidad política del Gabinete se encontraba totalmente organizado; la más mínima amenaza de impeachment era suficiente para provocar una dimisión. Así, por ejemplo, en I782, el ministro Lord North presentó su renuncia al cargo 
a raíz de una moción de censura aprobada por los Comunes y considerada susceptible de implicar el inicio de un procedimiento de impeachment.

\subsubsection{El juicio político en Estados Unidos}

El juicio político fue instituido en la Constitución Federal de los Estados Unidos de Norteamérica de 1787. Fue previsto expresamente para funcionarios públicos y por causales específicas como traición, cohecho, y otros delitos y faltas graves. La sección cuarta del artículo dos de la Constitución estadounidense, "El Presidente, el Vicepresidente y todos los funcionarios civiles de los Estados Unidos serán separados de sus puestos al ser acusados y declarados culpables de traición, cohecho u otros delitos y faltas graves.

Según el Senado de los Estados Unidos de Norteamérica, desde 1789 hasta la actualidad, sólo se han acusado a diecisiete funcionarios federales (los presidentes Johnson y Clinton, el senador Blount, el secretario de Guerra Belknap y trece jueces). De ellos, únicamente catorce concluyeron en el Senado, mientras que los tres casos restantes fueron declinados. Siete impeachments terminaron con la absolución del funcionario acusado, a la vez que en los otros siete (todos jueces) se les sancionó con la destitución de su cargo.

El caso del senador Blount en 1797; de carácter nacional, acusado por la Cámara de Representantes por, presuntamente, haber conspirado en contra de los intereses de su patria. En un primer momento, el Senado ordenó su prisión preventiva, poco después obtuvo su libertad bajo fianza. Luego el Senado se negó a conocer la situación aduciendo que un senador no podía ser sometido a un impeachment. (Gallo (1897), citado por García Chavarri (2013))

En 1804 se registra el impeachment contra el juez del distrito de New Hampshire John Pickering, siendo destituido de su cargo por conducta impropia (notoria incapacidad debida a su alcoholismo). En 1826, el juez James H. Peck fue acusado por conducta impropia y el Senado votó por su absolución el $3 \mathrm{I}$ de enero de I83I. Resultado contrario, el juez West $\mathrm{H}$. Humphreys fue destituido de su cargo - sin concurrir a ejercer su derecho de defensa.

En 1868, el presidente Andrew Johnson (1808 - 1875) fue acusado por haber removido a su secretario de Guerra Edwin Stanton sin el consentimiento del Senado, según lo establecía la restrictiva "Tenure of Office Act". Con treinta y cinco votos a favor de la acusación y diecinueve en contra, el presidente Johnson resultó absuelto (se libró de la sanción por sólo un voto).

En 1999 se recuerda el impeachment seguido contra el presidente William Jefferson Clinton por los cargos de perjurio y obstrucción a la justicia con ocasión de su vinculación con la, en ese momento, pasante de la Casa Blanca Monica Lewinsky. Al no obtener los votos necesarios para la mayoría calificada requerida (67 votos), el presidente Clinton fue absuelto por el Senado norteamericano el 12 de febrero de 1999.

En el 202I, se registra el juicio político el seguido contra el presidente Donald Trump, siendo el cuarto seguido a un Presidente de Estados unidos y el segundo a Trump; en este último fue acusado de "incitar a la insurrección", recuérdese, Trump, se negó a reconocer el triunfo electoral de Jhon Biden, cuyo epílogo fuera el ataque y asalto al Capitolio de Estados Unidos. Al final Trump, fue absuelto al no lograr la votación requerida, 57 senadores lo declararon culpable y 43 no culpable. Para la vacancia se requería dos tercios de los votos. 
Como puede observarse el impeachment en el sistema inglés y norteamericano busca sancionar políticamente ante un acto moral "que llegue a lesionar la dignidad de la función que el alto representante estatal está desempeñando". Por ello, entonces, su finalidad es la de reprimir con la destitución en el cargo a quien es indigno de él a causa de sus delitos y faltas graves.

El juicio político se diferencia del proceso penal, y es propio del ejercicio constitucional y competencial del Congreso. Por ello, es que el razonamiento pasa por la decisión política de los representantes del Congreso y está sujeto a la representatividad política del encausado y por ende al juicio de la mayoría sobre la minoría.

\subsubsection{El antejuicio en el Derecho Comparado Europa y América Latina}

A continuación, se describe lo sustentando por García Chavarri (20l3):

\section{El antejuicio en Alemania}

En el caso de Alemania, el artículo $61^{\circ}$ de La Constitución de la República Federal de Alemania, conocida como Ley Fundamental de Bonn prescribe: prevé la figura del antejuicio sólo para el Presidente Federal y los miembros del Bundestag (Congreso). Allí se indica: Que tanto el Bundesrat (Cámara alta) podrán acusarlo por violación dolosa de la Ley Fundamental o de otra ley federal. La solicitud de acusación deberá ser presentada, al menos, por una cuarta parte de los miembros del Bundestag (Cámara baja) o por una cuarta parte de los votos del Bundesrat. Asimismo, la resolución para formular dicha acusación requiere la mayoría de dos tercios de los miembros del Bundestag o de dos tercios de los votos del Bundesrat. Por último, la acusación estará representada por un delegado del órgano acusador.

\section{El antejuicio en España}

El artículo $102^{\circ}$ de la Constitución española de 1978 establece un modelo de antejuicio para los miembros del Gobierno y de las Cortes Generales (o sea, del Congreso de los Diputados y del Senado). El requisito de la acusación parlamentaria contra el Presidente y los demás miembros del parlamento son: por la imputación de traición o por cualquier delito contra la seguridad del Estado en el ejercicio de sus funciones. Esta acusación debe ser planteada por iniciativa de la cuarta parte de los miembros del Congreso, y con la aprobación de la mayoría absoluta.

\section{EI antejuicio en Italia}

En Italia, la Constitución, prevé formas de antejuicio para el Presidente de la República y para los miembros del Gobierno y del Parlamento. En caso del Presidente de la República, señala que este será acusado por el Parlamento, en sesión conjunta y requiere mayoría absoluta de sus miembros en casos de traición y violación de la constitución. Asimismo, el artículo $134^{\circ}$, numeral 3 indica que compete a la Corte Constitucional conocer estas acusaciones.

\section{El antejuicio en Costa Rica}

En Costa Rica, el artículo $112^{\circ}$ de la Constitución Política prescribe la figura de antejuicio para las principales autoridades del Estado. Confiere como atribución exclusiva de la Asamblea Legislativa: “(...) Admitir o no las acusaciones que se interpongan contra quien ejerza la Presidencia de la República, Vicepresidentes, miembros de los Supremos Poderes y Ministros 
Diplomáticos, declarando por dos terceras partes de votos del total de la Asamblea si hay o no lugar a formación de causa contra ellos, poniéndolos, en caso afirmativo, a disposición de la Corte Suprema de Justicia para su juzgamiento; (...)".

\section{El antejuicio en Guatemala}

La Constitución Política de la República de Guatemala de 1985 contempla el antejuicio para los miembros del Gobierno, así como para los funcionarios de mayor grado en la judicatura ordinaria y para los de cargos en organismos constitucionales. En los siguientes términos: "Artículo 165".- Atribuciones. Corresponde al Congreso de la República: [...] H. Declarar si ha lugar o no a formación de causa contra el Presidente y Vicepresidente de la República, Presidente y magistrados de la Corte Suprema de Justicia, del Tribunal Supremo Electoral, y de la Corte de Constitucionalidad, Ministros, Viceministros de Estado, cuando estén encargados del Despacho, Secretarios de la Presidencia de la república, Subsecretarios que los sustituyan, Procurador de los Derechos Humanos, Fiscal General y Procurador General de la Nación. Toda resolución sobre esta materia ha de tomarse con el voto favorable de las dos terceras partes del número total de diputados que integran el Congreso [...]."

\section{El antejuicio en Venezuela}

La Constitución de la República Bolivariana de Venezuela de 1999 prevé un modelo de antejuicio al establecer la competencia del máximo órgano judicial para el procesamiento penal de los altos funcionarios. Bajo los siguientes términos: “Artículo 266. Son atribuciones del Tribunal Supremo de Justicia: (...) 2. Declarar si hay o no mérito para el enjuiciamiento del Presidente o Presidenta de la República o quien haga sus veces, y en caso afirmativo, continuar conociendo de la causa previa autorización de la Asamblea Nacional, hasta sentencia definitiva. 3. Declarar si hay o no mérito para el enjuiciamiento del Vicepresidente o Vicepresidenta de la República, de los o las integrantes de la Asamblea Nacional o del propio Tribunal Supremo de Justicia, de los Ministros - Ministras, del Procurador o Procuradora General, del Fiscal o Fiscala General, del Contralor - Contralora General de la República, del Defensor o Defensora del Pueblo, los Gobernadores - Gobernadoras, oficiales, generales y almirantes de la Fuerza Armada Nacional y de los jefes o jefas de misiones diplomáticas de la República y, en caso afirmativo, remitir los autos al Fiscal o Fiscala General de la República o a quien haga sus veces, si fuere el caso; y si el delito fuere común, continuará conociendo de la causa hasta la sentencia definitiva. (...)”.

$\mathrm{Al}$ analizar los modelos de antejuicio en los diversos países descritos anteriormente; se observa que este proceso requiere la autorización del parlamento para el procesamiento penal de las autoridades políticas, judiciales y constitucionales del alto cargo del Estado por las conductas indebidas en el ejercicio de sus funciones. Diferenciándose del impeachment, en que el Parlamento no decide sanción contra la autoridad acusada. (García, 2013 pp 52-55)

\section{El antejuicio y juicio político en el Perú}

El antejuicio en el Perú, se encuentra normada en los artículos $99^{\circ}$ y $100^{\circ}$ de la Constitución Política, de acuerdo a ello, corresponde a la Comisión Permanente acusar ante el Pleno del Congreso a los altos funcionarios del Estado "Por infracción de la Constitución y por todo delito que cometan en el ejercicio de sus funciones y hasta cinco años después de que hayan cesado en estas". 
Según el Tribunal Constitucional: “(...) coexisten en Perú ordenamiento ambos institutos, 'antejuicio constitucional' y 'juicio político', pueden presentarse en la práctica hasta tres variables: a) puede haber casos en los que el Congreso de la República, sin estimar que hubo infracción a la Constitución empero si la comisión de delitos por parte de funcionarios de alto rango, disponga ponerlos a disposición del Fiscal de la Nación con el objeto de que este último formule denuncia ante la Corte Suprema, quien a su vez resolverá sobre su juzgamiento o, en su caso, sanción; b) puede haber casos en los que el Congreso, sin estimar que hubo conductas de tipo penal por parte de los altos funcionarios, quienes por tanto no se encuentran en condición de sometimiento a la vía penal, les imponga empero, sanciones de suspensión, inhabilitación o destitución, tras haber infringido la Norma Fundamental; $y, c)$ puede haber casos en los que el Congreso de la República, además de sancionar aquellos funcionarios de primer nivel, por infringir la Constitución, disponga concurrentemente y como consecuencia de haberse determinado su responsabilidad penal, se les ponga a disposición del Fiscal de la Nación a efectos de promover la denuncia correspondiente en la vía judicial penal" (Expediente 0340-1998AA/TC, fundamento jurídico 8 y 0358-1998-AA/TC, fundamento jurídico 7)

La acusación constitucional forma parte del control político destinado a garantizar la vigencia y eficacia de las instituciones previstas en la constitución contra el abuso de poder en que pudieran incurrir los altos funcionarios públicos. Asimismo, precisa en caso que se imputarán cargos de naturaleza delictiva y penal en el ejercicio de sus funciones prescribe la intervención de la Corte Suprema en el proceso de la investigación, juzgamiento y penalización.

\section{El “juicio político" o Acusaciones por "infracción de la Constitución”.}

El juicio político o acusación constitucional se encuentra normado en el artículo 99 de la Constitución Política, este es un procedimiento dirigido a los funcionarios del Estado en razón de las "faltas políticas" cometidas en el ejercicio de sus funciones.

Sar (2005) citando a Bidart Campos refiere: que, el juicio político no es un juicio penal, porque en este, no busca castigar un hecho delictivo, sino separar del cargo; "no tiene origen en la comisión de un delito, sino en la comisión de faltas que aminoran, en grado sumo, la confianza depositada en el funcionario, la que debe ir indefectiblemente ligada al cargo que ostenta".

Juristas como Paniagua, Quispe Correa, Alvarez Miranda, Valle Riesta, García Belaúnde en diferentes circunstancias cuestionan la indefinición de la "infracción inconstitucional". Paniagua en la defensa de los magistrados del Tribunal Constitucional separados del Cargo sostiene: "Nunca en el Perú, se acusó a nadie y menos se condenó, desde luego, por infracción de la Constitución. Y una razón existía para ello: hasta la Constitución de 1979”, la acusación se determinaba por delitos e infracciones que según ley debían penarse.

Quispe Correa citado por Sar (2005) se pregunta: ¿qué actos constituirían infracciones constitucionales? Y se responde señalando que no se ha especificado legalmente. Adiciona que “solo figura un extremo de 'pena' en la Constitución. Que llega hasta diez años de inhabilitación para ejercer función pública. Sin embargo, no existe una tabla que determine qué actos son infractorios y qué penas merecen. ¿En qué caso se aplicaría el máximo de la sanción y en qué otro caso existiría una punición menor? Nadie lo sabe. Este es un 'castigo' fundado en la subjetividad, cuyo origen es estrictamente político, lo que puede ser causa de arbitrariedades" 
Sar (2005) concluye citando a (Alvarez, 1999): La infracción de la Constitución es una acusación vaga e imprecisa que sirve como continente para cualquier clase de contenido, para cualquier clase de conducta, toda vez que no hay una prohibición o no hay una prohibición accesible al conocimiento de las personas de "inteligencia normal" como requería la Corte Suprema de los Estados Unidos en pronunciamiento que el Tribunal hizo propio. (p. 306).

De esto queda claro entonces que la figura de la "infracción constitucional" normada en el artículo 99 de al igual que el numeral 2 del artículo $113^{\circ}$ de la Constitución Política sobre la "vacancia por la permanente incapacidad moral y física", son figuras ambiguas y vagas, que pueden ser confundidas y prestarse a la arbitrariedad de los congresistas, por encontrarse indeterminadas. Las cuales merecen una normativa especial o bien una reforma constitucional.

\subsection{El concepto filosófico de moral}

Todos los sistemas filosóficos desde los presocráticos hasta la actualidad incorporan el estudio de la filosofía moral, etimológicamente el término moral se encuentra relacionado con el de ética; por lo que podemos observar una sinonimia entre ambos, la confusión de ambos términos se deben a su origen; porque ambos significan "costumbre" o "hábito", para los griegos es el ethos, en latín, es moris, mos.

\section{Teorías sobre la moral}

No existe acuerdo entre filósofos sobre la naturaleza, origen y razonamiento de qué es lo moral; ya desde la época antigua entre los filósofos griegos surge la disputa entre dos corrientes: el hedonismo y el eudemonismo moral. El primero postula, que el hombre actúa bajo sus impulsos, emociones e instintos para satisfacer sus necesidades evitando lo doloroso e indeseable por lo placentero para obtener la felicidad. Por lo contrario, el eudemonismo moral planteado por Sócrates, Platón y Aristóteles; sin renunciar a la búsqueda de lo placentero; conciben lo moral y ético alcanzar la felicidad. Pero no a cualquier costa, sino haciendo el bien, por lo que se trataría de una virtud humana.

Le corresponde a Aristóteles una concepción teleológica de la ética, argumentando que toda actividad natural tiende a un fin, y es el fin lo que mueve a la gente a obrar para alcanzar la felicidad, pero esta meta la logran los ciudadanos al hacer el bien por lo que se encuentra relacionada con la virtud. Para Aristóteles un hombre virtuoso sería aquel que aspira hacer el bien y evitar el mal. Asimismo, indica que la virtud, no es natural al hombre, como lo son las pasiones, sino que se forma y perfecciona con la práctica por lo tanto es un hábito que puede ser formado y perfeccionado. De ello se infiere; que la ética aristotélica, puede tener una doble fuente: puede ser racional e intelectual o emocional y pasional. Y, en el campo de la ética el hombre virtuoso será aquel que logre dominar, controlar la parte instintiva o irracional de su alma.

Es preciso mencionar que, para Aristóteles, las virtudes se ubican siempre en un término medio Entre dos vicios que representan el exceso y la deficiencia, así por ejemplo: La virtud del coraje se ubica entre los vicios de la cobardía (deficiencia) y de la temeridad (exceso), la virtud de la generosidad se ubica entre la avaricia (deficiencia) y la prodigalidad (exceso) y la virtud de la templanza se ubica entre la insensibilidad (defecto) y la auto indulgencia (exceso). Si bien esto, en general, es cierto, Aristóteles señalaba que, en muchos casos, el ejercicio de la virtud no admite un término medio. Así, no se plantea el caso del término medio en acciones que son 
ruines en sí mismas, y no por su exceso o defecto, tales como la envidia, el gozar de los males, el mentir, el adulterio, el robo o el homicidio. Tampoco puede haber un término medio de aquello que ya constituye un defecto o un exceso como la injusticia, la cobardía o el desenfreno (Montuschi, 2004).

\section{El realismo moral}

Representado por Platón y sus seguidores "sostiene que los principios morales tienen un fundamento objetivo que trasciende las meras convenciones humanas". Según esta postura los valores y los principios morales serían entidades abstractas inmanentes, universales de carácter espiritual (Montuschi, 2004).

\section{El escepticismo moral}

Esta corriente, vinculada al relativismo moral, niega el carácter objetivo de los valores morales, por lo que estaría condicionada al contexto cultural y a la convencionalidad social. Otro tipo de cuestiones de las que se ocupa la ética son las psicológicas. En este caso se trata de analizar cuáles son las motivaciones que impulsan a los seres humanos a comportarse moralmente.

\section{El psicologismo moral}

Bajo el psicologismo se presentan diferentes tendencias entre las que se encuentran: Aristóteles, Santo Tomas de Aquino, Thomas Hobbes, David Hume y Kant (Montuschi, 2004):

Para Aristóteles los seres humanos tienen una capacidad intuitiva natural que le lleva a aspirar el propósito de la existencia y alcanzar la felicidad. Santo Tomas de Aquino, siguiendo a Aristóteles, postula que los seres humanos por naturaleza tenemos la facultad de alcanzar las obligaciones morales. "Se trataría de algo así como una "conciencia moral natural" que permite reconocer a normas que estarían incorporadas en la naturaleza misma de los individuos".

Thomas Hobbes, postula que los actos humanos se encuentran motivados por los intereses individuales, esta posición es conocida como el "egoísmo psicológico". En oposición a las posturas del llamado "altruismo psicológico", para el cual actos humanos motivados por una benevolencia instintiva.

David Hume, desde una concepción emotivista del comportamiento moral, plantea que las emociones son las que nos motivan a actuar moralmente. Inmanuel Kant, en oposición a la postura de Hume sostiene que las acciones morales se basan en la razón, estando libre de ella, los deseos y las emociones.

\section{La ética normativa}

Esta corriente, se propone evaluar los principios morales formulando reglas y juicios acerca de lo que es bueno y correcto, busca establecer criterios de conducta moral que puedan ser aceptados por todos, logrando un universalismo ético, basado en el cristianismo basado en sus reglas de oro: "no hagas a otros lo que no quieras que te hagan a ti".

En el bloque de teorías normativas que se diferencian las de los valores morales de deberes o de derechos, en el caso de la teoría de las virtudes las teorías deontológicas llamadas también no consecuencialistas. Como se mencionó líneas arriba, la teoría de las virtudes se ubica en la formación del carácter de las personas. 
Desde estas diferentes perspectivas, nos preguntamos iEs posible establecer un criterio de consenso para establecer las reglas y criterios básicos de buena conducta moral, de los funcionarios del Estado incluyendo al Presidente de la República, a aceptado por todos los ciudadanos?

\subsection{Teorías deontológicas}

Las teorías deontológicas de la moralidad se basan en principios fundamentales de obligaciones que tenemos que cumplir con independencia de las consecuencias de las acciones que puedan derivarse. Estas teorías se las conoce también como no consecuencialistas. Se distinguen cuatro tipos de teorías deontológicas.

Montuschi (2004) considera pertinente precisar que, para la fundamentación y justificación de la vacancia por incapacidad moral debe priorizarse el conocimiento de las Teorías deontológicas, que a continuación se describen.

\subsection{Teoría de los deberes}

Representada por los filósofos y juristas Hugo Grotius (1625) y Samuel Pufendorf ( 1672 ), quienes consideran que las personas tenemos una serie de deberes adquiridos de forma natural. Esos deberes pueden ser: hacia Dios (honrarlo, servirlo y rezarle), hacia uno mismo (preservar la vida, buscar la felicidad y desarrollar talentos) y hacia otros. En este último caso se pueden distinguir deberes familiares (honrar a los padres y cuidar al cónyuge y a los hijos), deberes sociales (no dañar a otras personas, cumplir las promesas y ser benevolente) y deberes políticos (obedecer las leyes y tener espíritu cívico) (Montuschi, 2004).

\subsubsection{Teoría de los derechos}

Los representantes más importantes de las teorías deontológicas, sin lugar a dudas son: Jhon Locke e Inmanuel Kant. Kant es el filósofo que da un giro copernicano a la filosofía de la moral. Para Kant, la moral forma parte de las acciones humanas de tipo racional "basadas en un principio supremo de moralidad. "Ese es el imperativo categórico que sostiene que todas las personas tienen naturalmente ciertos derechos que todos deben reconocer y respetar".

El imperativo categórico es la ley moral incondicional que dicta el curso de las acciones, sin importar las consecuencias que puedan resultar. Kant sostiene la universalidad de la justificación racional de la acción y formula el imperativo categórico, que debe ser único, en su versión más general: "Obra sólo según una máxima tal que puedas querer al mismo tiempo que se torne ley universal".

Kant, en sus obras: La crítica de la razón práctica, Fundamentación de la metafísica de las costumbres; traza magistralmente las máximas sobre el accionar humano en la cual una acción sería buena sólo como medio para alcanzar algún fin específico, esta actuación es moral, cuando se cumple con nuestros deberes con responsabilidad, libertad, autonomía, buscando el bienestar de los demás, teniendo en cuenta la dignidad humana.

El hombre, y en general todo ser racional, existe como fin en sí mismo, no sólo como medio para usos cualesquiera de esta o aquella voluntad; debe en todas sus acciones, no sólo las dirigidas a sí mismo, sino las dirigidas a los demás seres racionales, ser considerado siempre al mismo tiempo como fin. Cf Kant, I., Fundamentación de la metafísica de las costumbres, I785. 
En oposición a la moral utilitarista, lo que vuelve correcta a una acción no es el bien o la utilidad que de la misma se deriva. Una acción es moral cuando tiene algún aspecto que corresponde a lo que Ross denomina deberes prima facie. Entre los que se destacan: fidelidad (deber de cumplir promesas), reparación (deber de compensar a terceros cuando les producimos un daño), gratitud (deber de agradecer a quienes nos ayudan), justicia (deber de reconocer el mérito), beneficencia (deber de mejorar la condición de otros), automejora (deber de mejorar nuestras virtudes y nuestra inteligencia) y no-maleficencia (deber de no dañar a otros).

Entonces, si es posible valorar y motivar la incapacidad moral, ya que ella se encuentra comprendida en los deberes de función y responsabilidad en ejercicio de las funciones del Presidente de la República; las cuales una vez más no se encuentran determinadas en la Constitución Política del Perú. Por lo que, esta es otra vía para resolver el problema de la indeterminación conceptual de la vacancia por incapacidad moral.

\subsection{Teorías consecuencialistas o teológicas}

De acuerdo con estas teorías nuestras acciones para ser valoradas como moralmente correctas requiere de las personas que actúen de modo de producir el mayor bien en general. Existen tres tipos de teorías consecuencialistas: el egoísmo ético, el altruismo ético y el utilitarismo.

El egoísmo ético, postula que una acción es moralmente correcta si el resultado de la misma es favorable para quien la lleva a cabo. "Por el contrario, el altruismo ético sostiene que la acción moralmente correcta es aquella que tiene consecuencias favorables para todos excepto para quien la ejecuta" (Montuschi, 2004).

\section{La teoría del contrato social de Thomas Hobbes}

Considerada como una variante de las teorías anteriores, es representada por Thomas Hobbes. Quien, postula que por razones puramente egoístas e individuales, las personas tuvieran una mejor vida en un mundo regido por reglas morales que en uno sin ellas. “...será por razones puramente egoístas que se acordará respecto de los medios de cumplimiento y de los castigos para quienes violen las reglas".

\section{La teoría de la justicia distributiva de Rawls y Nozick}

Rawls y Nozick, consideran a la justicia y la libertad como los mayores valores. Rawls considera la "equidad" como el valor que debería regir el contrato social en el que se debería aplicar tres principios: el principio de igual libertad, el principio de diferencia y el principio de igualdad de oportunidades.

Nozick, por su parte, considera a la libertad como el mayor valor. En materia de justicia distributiva sostiene el principio de que una distribución es justa si todos tienen derecho a las propiedades que poseen bajo dicha distribución. $Y$ ese derecho se obtiene cuando se adquiere una propiedad de acuerdo con a) el principio de justicia en la adquisición; b) el principio de justicia en las transferencias recibidas de alguien que tenía el derecho de propiedad y c) no hay otros derechos sino los obtenidos por aplicaciones sucesivas de a) y b) (Montuschi, 2004).

\section{Teoría del utilitarismo}


Los filósofos ingleses Jeremy Bentham (I748-1832) y John Stuart Mill (1806-1873), son considerados como los representantes más importantes de esta teoría, en el que el supuesto central es el "principio de utilidad" de acuerdo con el cual el criterio que debe adoptarse para valorar las acciones debe ser el aumento o disminución de la felicidad que promueven, entendiendo felicidad como placer.

John Stuart Mill (1806-1873), seguidor de Bentham postula el enunciado: "Las acciones son correctas en la medida en que tiendan promover el mayor bien para el mayor número". En resumen, para esta teoría cuenta los resultados y la utilidad lograda, sin importar los medios; por lo cual el hombre podría ser utilizado como tal. El principio de utilidad puede ser aplicado en las consecuencias derivadas de la acción y en el cumplimiento de las reglas referidas al logro del bien o felicidad para el mayor número de personas.

Aún en aplicación del razonamiento moral utilitarista en el caso de la incapacidad moral para la vacancia presidencial bajo ambos enfoques, la actuación irresponsable de un funcionario o de un Presidente de la República, podría ser valorada en función de si esta acción ha sido motivada por el interés individual, "egoísta" de beneficiarse del poder, perjudicando amplios sectores sociales.

\subsection{Jurisprudencia del TC sobre permanente incapacidad moral o física (STS 006-2003)}

La jurisprudencia registra el pronunciamiento del Tribunal Constitucional emitida a través de (STS 006-2003) sobre la vacancia presidencial por permanente incapacidad moral en la que falla invocando al Congreso, legislar sobre el procedimiento y el número de votos requeridos para la declaratoria de vacancia por incapacidad moral; en los siguientes términos (Tribunal Constitucional, 2003):

Este Colegiado debe resaltar que no existe procedimiento ni votación calificada alguna para que el Congreso de la República pueda declarar vacante el cargo de Primer Mandatario por la causal prevista en el inciso 2) del artículo $113^{\circ}$ de la Constitución, esto es, por "su permanente incapacidad moral o física". Ello, desde luego, no podría significar que el más alto cargo de la Nación pueda quedar vacante como consecuencia de mayorías simples, pues ello sería atentatorio del principio de razonabilidad, pudiéndose presentar supuestos absolutamente inaceptables en un Estado social y democrático de derecho, tales como el hecho de que mientras que el Congreso necesite de la votación de más de la mitad de su número legal de miembros para remover a los ministros (responsables políticamente y no elegidos por el pueblo), mediante el voto de censura, sin embargo, no necesite sino una mayoría simple para remover al Presidente de la República (quien no tiene responsabilidad política y es elegido directamente por la voluntad popular). En ese sentido, el Tribunal Constitucional exhorta al Congreso de la República a legislar un procedimiento y la necesidad de una votación calificada para poder declarar la vacancia presidencial por la causal prevista en el inciso 2 ) del artículo $113^{\circ}$ de la Constitución, a efectos de no incurrir en aplicaciones irrazonables de la referida disposición constitucional, para cual, al igual que en los casos de juicio político, debe estipularse una votación calificada no menor a los 2/3 del número legal de miembros del Congreso (Foros Perú, 2017).

Igualmente es importante mencionar el fallo del Tribunal Constitucional (Sentencia 778/2020 Expediente 00002-2020-CC/TC) en relación a la acción de inconstitucional en materia competencial interpuesta por el Procurador Público del Ejecutivo en contra del congreso de la 
República sobre la vacancia por incapacidad moral del ex presidente Martín, Alberto Vizcarra Cornejo.

El Tribunal falla, declarando improcedente la acción de inconstitucional argumentando entre otras cosas:

La correcta interpretación de la incapacidad moral como causal de vacancia de la presidencia de la República es aquella que la identifica con "la falta de aptitud legal para continuar ejerciendo el cargo, por haberse acreditado objetivamente una conducta pública o social gravemente venal, corrupta, licenciosa u ofensiva a las convicciones ética de la ciudadanía, que deja constancia de una atrofia de las nociones de corrección e integridad de ánimo". Por ello, la incapacidad moral es, en definitiva, una situación pública que hace evidente la incapacidad hasta el extremo de interferir las funciones presidenciales y hacer aconsejable su remoción. Para estos efectos, señala que la permanente incapacidad moral declarada por el Congreso tiene que ser puesta en sus justos términos: es una decisión política, no técnica, que toma el Congreso, pero en función de una realidad existente que es atribución suya valorar. Por lo tanto, manifiesta que claramente el Constituyente ha confiado al Parlamento ser intérprete de esta causal ante la comunidad política, de modo exclusivo y excluyente. A él le corresponderá determinar la existencia o no de una situación política que califique como incapacidad moral del presidente de la República suficientemente grave como para justificar vacancia de la presidencia (Armas Viera \& Dávila Alvarado, 2021).

De esta manera en un fallo de mayoría simple el TC, determina la suscripción de la materia, indicando que no existiría conflicto de competencias, ya que son atribuciones del Congreso de la República prescritas en el inciso 2 y artículo $113^{\circ}$ de la Constitución. El Tribunal, precisa, además, que la vacancia por incapacidad moral "es una decisión política, no técnica".

Al criterio del autor, el TC perdió la oportunidad de establecer los criterios de contenido para aclarar los términos relacionados a "incapacidad moral".

\section{Conclusiones}

La incapacidad moral como causal de vacancia presidencial es una figura que no tiene antecedentes en las Constituciones de los diferentes países, en el sistema presidencial norteamericano y en los países latinoamericanos la cesación en las funciones del Presidente se encuentra normado como juicio político o Impeachment, formando parte de la acusación constitucional iniciado en la cámara de diputados y sancionada por la cámara de senadores. Cómo es sabido en Perú el congreso es unicameral, por lo que la acusación constitucional en la práctica es instancia única, ya que la Acusación los tramita la Comisión permanente, para luego ser resuelta por el Pleno del Congreso necesitando 87 votos para su aprobación requerida 2/3 de 130 congresistas). La unicameralidad, podría ser un factor que posibilite al legislativo tomar decisiones no muy bien pensadas, llevándolo a cometer errores y abusar del poder.

La vacancia presidencial por incapacidad moral, en Perú; por lo general evidencian el conflicto y lucha por el poder entre el Ejecutivo y el Legislativo, manifestando falta de criterios para la aplicación de los principios de separación y equilibrio de poder, pesos y contrapesos entre poderes del Estado. En el caso del ex Presidente Vizcarra no escapa a esta situación, si los congresistas consideraban vacarlo motivados por el incumplimiento del deber y la 
responsabilidad en sus funciones, en este caso se trataría de delitos de función comprendidos en los artículos $99^{\circ}$ y $100^{\circ}$ de la Constitución Política, por lo que se trataría de un juicio político, produciéndose superposición con lo prescrito el inciso 2 , artículo $113^{\circ}$ de la Cosntitución Política.

Por otra parte, las constituciones de los países latinoamericanos establecen la vacancia o cesación de sus funciones por "incapacidad física y mental", debidamente comprobada por una junta médica, la cual debe ser aprobada por el Congreso. La incapacidad moral como causal de vacancia rompe con este criterio y frente a ello caben dos opciones. La primera, sería entender a la incapacidad moral como una incapacidad de tipo mental. La segunda, sería entenderla para sancionar aquellas conductas negativas graves, pero que escapan de los alcances de la infracción constitucional y del juicio político, establecidas en los artículos $99^{\circ}$ y $100^{\circ}$ de la Constitución.

Es pertinente que se precise conceptualmente los contenidos de las figuras referidas a la vacancia presidencial por incapacidad moral a fin de evitar las ambigüedades, duplicidades y superposiciones jurídicas, entre el "juicio político", "antejuicio político", "la vacancia por incapacidad moral" y la "vacancia por incapacidad física y mental". Asimismo, en el marco del Estado de Derecho Constitucional, debe aprobarse un proceso de Reforma constitucional, que haga precisiones sobre el sistema político peruano. Regulando sobre ¿Qué modelo seguir el presidencialismo o el parlamentarismo?, ¿Qué adoptar la bilateralidad o la unilateralidad?, ¿Qué instituciones deben prevalecer para el equilibrio y contrapeso de poderes?

\section{Referencias bibliográficas}

Armas Viera, L., \& Dávila Alvarado, A. (202I). "Vacancia del presidente de la república por incapacidad moral”. Pleno. Sentencia 778/2020 Expediente 00002-2020-CC/TC. Sentencia del Tribunal Constitucional [Universidad Científica del Perú]. http://repositorio.ucp.edu.pe/handle/UCP//444

Bregaglio, R., Constantino, R., Arce, T., Castilla, M., Ruiz, J., Cosme, C., \& Fabiana, C. (202I). La causal de vacancia presidencial por incapacidad física y moral y su relación con la discapacidad. Revista Latinoamericana en Discapacidad, Sociedad y Derechos Humanos, 5(I), 8-26. http://redcdpd.net/revista/index.php/revista/article/view/250/I45

Domingo García, B. (1991). Forma de gobierno en la Constitución peruana. Revista de Estudios Políticos, 74, 6I5-632.

http://www.cepc.gob.es/Publicaciones/revistas/revistaselectronicas?IDR=3\&IDN=23 I \&ID $A=16703$

Foros Perú. (2017). Vacancia presidencial: Incapacidad moral debe probarse. Política. https://www.forosperu.net/temas/vacancia-presidencial-incapacidad-moral-debeprobarse. I I 7856I/pagina-4

García Chavarri, A. (2013). La vacancia por permanente incapacidad moral del Presidente de la República. Advocatus, 29, 97-108.

https://revistas.ulima.edu.pe/index.php/Advocatus/article/view/4238

Guerra-Cerrón, M. E. (20I8). Summa Procesal Civil (I ra ed.). Nomos \& Thesis E.I.R.L.

León Hilario, L. (2017). ¿Qué es y de dónde proviene la denominada "incapacidad moral”? LA LEY. https://laley.pe/art/4500/-que-es-y-de-donde-proviene-la-denominada-Idquo-incapacidad- 
moral-rdquo-

Melgar Bendezú, A. R. (2019). Relaciones de conflicto entre los órganos ejecutivo y legislativo en el Perú y el mecanismo de disolución parlamentaria: análisis y propuesta [Pontificia Universidad Católica del Perú]. http://hdl.handle.net/20.500.12404//4519

Mezarino, M. (s. f.). Filosofia. Scribd. https://es.scribd.com/document/408504450/FILOSOFIA-pdf

Montuschi, L. (2004). NEtica y razonamiento moral. Dilemas morales y comportamiento ético en las organizaciones. Serie de Documentos de Trabajo. Universidad del Cema. https:/lucema.edu.ar/publicaciones/download/documentos/219.pdf

Quintero Jaramillo, T., \& López Viteri, J. G. (2018). Incapacidad fisica o mental causas de cesación de funciones del presidente del Ecuador. [Universidad de Especialistas Espíritu Santo]. http://repositorio.uees.edu.ec/I 23456789/2805

Sar, O. (2005). El antejuicio, el juicio político y la vacancia presidencial analizados a partir de la sentencia de inconstitucionalidad del inciso j del artículo 89 del reglamento del Congreso. lus Et Veritas, 15(3I), 296-306.

https://revistas.pucp.edu.pe/index.php/iusetveritas/article/view/I 2425

Sierra Casanova, R. (202I). La crisis peruana: perspectiva constitucional. YachaQ Revista de Derecho, I2, 197-202. https://doi.org//0.5 I343/yq.vil 2.780

Tribunal Constitucional, Pub. L. No. EXP. N.O 0006-2003-AllTC LIMA (2003).

Tribunal Constitucional, Pub. L. No. Sentencia recaída en el Expediente $N^{\circ}$ 0002-2020-CC/TC (2020).

\section{Financiamiento}

Ninguno.

\section{Conflicto de intereses}

El artículo no presenta conflicto de intereses.

\section{Contribución de autores}

Bardales-del-Aguila, Lionel: Investigador y redactor del presente artículo. 